\title{
Angiographic Severity of Coronary Artery Disease in Diabetic and Non-Diabetic Patients in a Tertiary Care Centre
}

TANJIMA PARVIN ${ }^{1}$, KMHS SIRAJUL HAQUE ${ }^{2}$, MD ABU SIDDIQUE ${ }^{1}$, SMAHSAN HABIB ${ }^{1}$, MUKHLESUR RAHMAN $^{1}$, MOHAMMAD HAFIZUR RAHMAN ${ }^{3}$, MD ASHRAF UDDIN SULTAN ${ }^{1}$, MD HARISUL HOQUE ${ }^{1}$

${ }^{1}$ Department of Cardiology, Bangabandhu Sheikh Mujib Medical University (BSMMU), Dhaka. ${ }^{2}$ Department of Cardiology, Anwar Khan Modern Medical College, Dhaka. ${ }^{3}$ Department of Biochemistry, Dhaka Medical College (DMC), Dhaka

Address of Correspondance: Dr. Tanjima Parvin, Assistant Professor, Department of Cardiology, Bangabandhu Sheikh Mujib Medical University (BSMMU), Dhaka. E-mail: tanjimaparvin@gmail.com

\begin{abstract}
:
Objective: Diabetes mellitus, a common metabolic disorder, is often associated with severe coronary artery disease. In this study, we compared the angiographic severity of coronary artery disease in diabetic patients compared with that of non diabetic patients.Methods: This observational study comprised of 102 subjects who had coronary artery disease on coronary angiography in the Department of Cardiology, Bangabandhu Sheikh Mujib Medical University (BSMMU), Dhaka, Bangladesh from January 2009 to December 2009. The patients were divided into two groups: one group with 24 (23.5\%) diabetic patients and another group with 78 (76.5\%) non diabetic patients. Demographic, clinical, laboratory and angiographic data were analyzed and compared between two groups. Results: Mean age \pm SD of the study subjects was 52.8 \pm 9.5 years and 94 (92\%) of them were male. Diabetic patients were older (mean age $\pm S D$; $57.6 \pm 9.5$ versus $51.3 \pm 9.9$ years; $p$ 004), and had higher frequency of hypertension (75\% versus $50 \%$, p 0.036), chronic stable angina (71\% versus $41 \%, p$ 0.018), and lower frequency of smoking (42\% versus $67 \%, p$ 0.034) and acute coronary syndrome (29\% versus $59 \% ; p 0.018$ ) in comparison to non diabetic patients. Left main stem disease (21\% versus $5 \%$, p 0.031 ) and three-vessel disease (50\% versus $31 \%$, p 0.094 ) were more prevalent in diabetic patients. Severe coronary artery stenosis was significantly more present in diabetics than non diabetics (Gensini score, $50.9 \pm 29.9$ versus 32.6 $\pm 21.9, p$ 0.001).Conclusion: Diabetic patients are more likely to have severe and extensive coronary artery disease. Left main stem and triple vessel disease are more commonly seen in diabetic patients compared to non diabetic patients.
\end{abstract}

Key words: diabetes mellitus, coronary angiography; coronary artery disease.

Introduction:

Coronary artery disease (CAD) is an important medical and public health problem with an approximately 7.2 million deaths/year, or $12 \%$ of all deaths worldwide annually and the single most important cause of death in developed countries. Rapid urbanization, life style change and economic growth in developing countries have led to a substantial increase in coronary heart disease (CHD). ${ }^{1}$ Like other developing countries, the prevalence of ischemic heart disease (IHD) is increasing in Bangladesh and emerged as an important cause of mortality and morbidity with reported incidence of 3.3/1000 populations and 100/ 1000 adult populations in 1975 and 2002, respectively. 2,3

Diabetes mellitus (DM) is an important risk factor for coronary heart disease. Cardiac involvement in diabetes commonly manifest as coronary artery disease (CAD) and less commonly as diabetic cardiomyopathy and cardiac autonomic neuropathy. Compared with non diabetic individuals, diabetic patients have a twofold to fourfold increased risk for development and dying of CHD. Diabetes is associated with an increased risk for MI and has worse cerebrovascular (CVD) outcomes after ACS events. Rising frequency of CAD in diabetic patients has been widely documented in hospital, autopsy, and epidemiological as well as longitudinal studies in several populations. Association of more extensive CAD with DM has been described in post-mortem, angiographic and IVUS-based studies and in studies with multi-slice coronary computed angiography. 4

Coronary angiography (CAG), the gold standard for the diagnosis and characterization of CHD, offers therapeutic options and determines prognosis. Heterogeneity of the composition, distribution, and location of atherosclerotic plaque within the coronary arteries also help predict procedural outcome and complications after PCI. ${ }^{5}$ Criteria established by a joint American College of Cardiology/ American Heart Association (ACC/AHA) task force suggested that procedure success and complication rates are related to a number of different lesion characteristics. ${ }^{6}$ 
Hence, this study was designed to see the severity of coronary artery disease in diabetic patients with coronary heart disease in a tertiary hospital in Bangladesh and compare them with that of non-diabetic patients in the same setting.

\section{Methods:}

Study population: This observational study comprised of 102 subjects who had coronary artery disease on coronary angiography in the Department of Cardiology, Bangabandhu Sheikh Mujib Medical University (BSMMU), Dhaka, Bangladesh from January 2009 to December 2009. The patients were diagnosed based on history, clinical presentation, ECG, echocardiogram, laboratory investigations, stress tests and angiography. All patients with CAD were divided into 2 groups: one group with 24 diabetic patients and another group with 78 non diabetic patients. The exclusion criteria were the presence of valvular heart disease, left ventricle hypertrophy, cardiomyopathy, congestive heart failure and a positive history of concomitant malignancies, liver and kidney diseases.

Study Protocol: Demographic data including sex, age, hypertension, dyslipidemia, smoking, and family history of CAD, in addition with the results of biochemical examinations were recorded in questionnaire form and analyzed. Medication history of the patients in each group was also recorded. Informed written consent was taken for all patients.

Definitions: Diabetes mellitus and other risk factors such as hypertension, dyslipidemia, smoking and family history of premature CAD were defined on the basis of standard definitions. ${ }^{7}$ Acute coronary syndrome (ACS) included
ST elevated myocardial infarction (STEMI) having ST elevation in ECG and a rise in cardiac markers, non-ST elevated myocardial infarction (NSTEMI) having evidence of myocardial necrosis and unstable angina (UA) presenting with a recent history of angina at rest or minimum exertion or crescendo angina not exceeding 3 months. Chronic stable angina (CSA) was defined as having a minimum 2-year history of typical stable angina (predictable and reproducible central chest discomfort after physical exertion and or emotional stress and is relieved by rest or sublingual nitroglycerin) with positive ETT. Significant CAD was defined as e" 70\% luminal diameter stenosis in one or more major epicardial vessels or e” $50 \%$ luminal diameter stenosis in left main stem (LMS). ${ }^{8}$ Assessment of the severity of coronary artery disease was done using Gensini score. ${ }^{9}$

Statistical Analysis: Statistical analyses were done using SPSS 17.0 (Statistical Package for Social Sciences). Continuous variables were expressed as mean \pm SD and were compared between groups by student's 't' test. Categorical variables were number (\%) and compared using a chi-square test or Fischer's exact test as appropriate. All $\mathrm{P}$ values were two-tailed with significance defined as $\mathrm{p}<$ 0.05 at the level of $95 \%$ confidence interval CI.

\section{Result:}

In table I demographic characteristics of the study subjects are listed. Diabetic patients had a significantly higher mean age than that of non diabetics ( $p$ 0.004). Frequency of hypertension was significantly more in diabetics than non diabetics ( $p$ 0.036) but smoking was more prevalent in non diabetics than diabetics ( $p$ 0.034). The prevalence of family history of CAD ( $p$ 0.147) and dyslipidemia ( $p$ 0.229), were similarly distributed in both groups.

Table-I

Baseline characteristics of the study subjects

\begin{tabular}{lcccc}
\hline Parameter & Total & $\begin{array}{c}\text { Diabetic patients } \\
\mathrm{n}=24\end{array}$ & $\begin{array}{c}\text { Non-diabetic patients } \\
\mathrm{n}=78\end{array}$ & P value \\
\hline $\begin{array}{l}\text { Mean age (yr) } \\
\text { Sex }\end{array}$ & $52.8 \pm 9.5$ & $57.6 \pm 6.7$ & $51.3 \pm 9.9$ & 0.004 \\
Male & $94(92)$ & $20(83)$ & $74(95)$ & 0.086 \\
Female & $8(8)$ & $4(17)$ & $4(5)$ & \\
Risk Factors & & & & \\
Hypertension & $57(56)$ & $18(75)$ & $39(50)$ & 0.036 \\
Smoking & $62(61)$ & $10(42)$ & $52(67)$ & 0.034 \\
F/H of CAD & $20(20)$ & $2(8)$ & $18(23)$ & 0.147 \\
Dyslipidemia & $84(82)$ & $22(91)$ & $62(79)$ & 0.229 \\
\hline
\end{tabular}

Data are mean $\pm(\mathrm{SD})$ for continuous and $n$ (\%) categorical variables. 
Table-II

Clinical presentation of the study subjects

\begin{tabular}{lcccc}
\hline $\begin{array}{l}\text { Parameter } \\
\text { Clinical presentation }\end{array}$ & Total & $\begin{array}{c}\text { Diabetic patients } \\
\mathrm{n}=24\end{array}$ & $\begin{array}{c}\text { Non-diabetic patients } \\
\mathrm{n}=78\end{array}$ & P value \\
\hline CSA & $49(48)$ & $17(71)$ & $32(41)$ & 0.018 \\
ACS & $53(52)$ & $7(29)$ & $46(59)$ & \\
STEMI & $31(30)$ & $4(17)$ & $27(35)$ & 0.129 \\
NSTEMI/UA & $22(22)$ & $3(13)$ & $19(24)$ & 0.268 \\
\hline
\end{tabular}

Data are n (\%) for categorical variables.

Table-III

Angiographic characterstics of the patients

\begin{tabular}{|c|c|c|c|c|}
\hline Parameter & Total & $\begin{array}{c}\text { Diabetic patients } \\
n=24\end{array}$ & $\begin{array}{l}\text { Non-diabetic patients } \\
\qquad \mathrm{n}=78\end{array}$ & P value \\
\hline \multicolumn{5}{|l|}{ Extent } \\
\hline SVD & $46(45)$ & 8(33) & $38(49)$ & 0.242 \\
\hline DVD & $20(20)$ & $4(16)$ & $16(21)$ & 0.777 \\
\hline TVD & $36(35)$ & $12(50)$ & $24(31)$ & 0.094 \\
\hline LMS & $6(6)$ & $5(21)$ & $4(5)$ & 0.031 \\
\hline \multicolumn{5}{|c|}{ Vessel involvement } \\
\hline RCA & $60(59)$ & $17(70)$ & $43(55)$ & 0.236 \\
\hline LAD & $77(75)$ & 21(87) & $56(71)$ & 0.175 \\
\hline LCX & $49(48)$ & $12(50)$ & $37(47)$ & 1.000 \\
\hline Stenosis score & $36.9 \pm 25.1$ & $50.9 \pm 29.9$ & $32.6 \pm 21.9$ & 0.001 \\
\hline
\end{tabular}

Data are mean $\pm(\mathrm{SD})$ for continuous and $\mathrm{n}(\%)$ categorical variables.

Table II shows clinical presentation of study subjects with significantly higher frequency of chronic stable angina (71\% versus $41 \%$ ) in diabetics, and acute coronary syndrome (59\% versus 29\%) in non diabetics (p 0.018). Both STEMI and NSTEMI/UA were more in non diabetics than diabetics with no significant difference (p 0.129 and p 0.268 respectively).

Table III shows the distribution of angiographic findings of the study subjects. Left main stem and TVD was more in diabetics than in non diabetics (21\% versus 5\%, p 0.031 and $50 \%$ versus 31\%, p 0.094) while SVD and DVD were more in non diabetics than diabetics. CAD involving major coronary vessels was similarly distributed in both groups. Severe coronary artery disease was significantly more in diabetics than in non diabetics (Gensini stenosis score

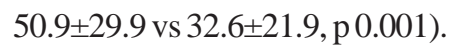

\section{Discussion:}

The study focused on risk factors, clinical presentation and angiographic characteristics of coronary artery disease in diabetic patients compared with that of non diabetic patients in a tertiary care centre.
Among the study subjects, 24 (23.5\%) were diabetic and the rest non diabetic. Similar prevalence of diabetes mellitus with coronary artery disease was also reported by Jinnah et $\mathrm{al}^{10}(23.7 \%)$ and Shah et al ${ }^{11}(27.1 \%)$ although it differed in the studies by Peter el $\mathrm{al}^{12}(10.3 \%)$, Hoque et $\mathrm{al}^{13}$ (40\%) and Mahadeva et $\mathrm{al}^{14}$ (60.1\%).

The mean age of diabetic subjects differed significantly from that of non diabetics (p value 0.004). Similar result was found by Shah et al ${ }^{11}$ This finding is consistent with the fact that diabetes is associated with older age, and this, in turn, with higher prevalence of CHD. However, Muataz $\mathrm{FH}^{15}$ and Morteza et $\mathrm{al}^{16}$ showed no significant difference of mean age between diabetic and non diabetic patients.

Gender distribution in this study showed no significant difference ( $p$ value 0.086 ) in diabetic versus non diabetic group. In both, males were more commonly affected than females with a higher percentage of females in diabetic than in the non diabetic. Similar gender distribution was also reported by Muataz $\mathrm{FH}^{15}$. This high prevalence of IHD in males compared to females in both groups in the 
present study may be due to small number of patients which might not be representative of our population.

In this present study, proportion of hypertension among diabetics was found to be significantly higher as compared to non-diabetics (75\% vs 50\%, P < 0.05) and that of smoking in non diabetics than in diabetics (67\% vs 42\%, $\mathrm{P}$ $<0.05)$. On the other hand, there were no statistically significant differences between diabetics and non diabetics for the presence of hypertension and family history of CHD (p values 0.07 and 0.06 respectively). Similar observations were also reported by Shah et $\mathrm{al}^{11}$ and Peter el $\mathrm{al}^{12}$ in their studies. Mahadeva et $\mathrm{al}^{14}$ mentioned higher prevalence of dyslipidemia in diabetics ( $p$ 0.03) and smoking in non diabetics (p 0.01) and no difference for hypertension and family history between them. Mahdi et al $^{17}$ showed that diabetics had higher prevalence of hyperlipidemia compared with non diabetics, and no difference was found for the presence of hypertension, smoking and family history.

This study showed CSA in diabetics and ACS in non diabetics as the main clinical presentation (p 0.018) but no significant difference of STEMI (p 0.129) and UA/ NSTEMI (p 0.268) in diabetic versus non diabetic patients. Bogaty et $\mathrm{al}^{7}$ and Safiuddin ${ }^{18}$ mentioned similarly stable angina as main presentation in diabetes group. Javidi D et $\mathrm{al}^{19}$ showed STEMI or NSTEMI as main clinical presentation in diabetics in comparison with non diabetics. Shah et $\mathrm{al}^{11}$ and Kassaian et $\mathrm{al}^{20}$ mentioned no significant association of diabetes between ACS and CSA. Peter el $\mathrm{al}^{12}$ and Muataz $\mathrm{FH}^{15}$ showed similar prevalence of stable angina, STEMI and NSTEMI/UA in diabetics and non diabetics. As this study was conducted in a tertiary referral center, the prevalence of clinical presentation in this study may not be representative of the true prevalence of each clinical presentation.

In this study, diabetic patients had higher percentage of left main stem disease (p 0.031) and three-vessel disease (p 0.094) and less single- and two-vessel disease as compared with non diabetic patients (38\% vs $47 \%$ and $16 \%$ vs $21 \%$, respectively). This finding is consistent with that of Muataz et $\mathrm{al}^{15}$. Mahdi et $\mathrm{al}^{17}$ mentioned higher distribution of TVD and lower distribution of SVD and DVD in diabetics. Srinidhi et al ${ }^{21}$, in acute coronary syndrome, found significant association of similar diseased vessels in diabetics in comparison to non diabetics. Javidi et $\mathrm{al}^{19}$ that showed that diabetic patients had a higher incidence of three-vessel coronary disease but regarding left main coronary artery disease, no difference was found between the two groups. Hoque et $\mathrm{al}^{13}$,however, found higher prevalence of SVD and TVD and low prevalence of DVD in diabetics than in non diabetics. The commonest vessel involved in both the groups was LAD, 87\% in diabetes and $71 \%$ in non diabetic, followed by RCA and LCX. Similar vessel involvement with varying percentage was also reported in the study by Hoque et $\mathrm{al}^{13}$.

In term of severity of coronary artery disease, Gensini score in our study was significantly higher in diabetics

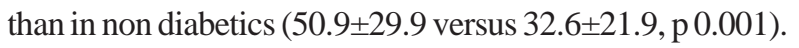
This finding is consistent with Mahadeva et $\mathrm{al}^{14}$ and $\mathrm{V}$. Peppes et $\mathrm{al}^{22}$ who found significant association of severe coronary artery disease in patients with diabetes mellitus in comparison to non diabetes patients. In a study by Cezary et al $^{23}$ no significant association between Gensini score and diabetes mellitus was found with paients over 80 years of age.

The results showed that there is a statistically significant higher severity of CAD in subjects with diabetes than non diabetics. Coronary artery disease in diabetics is characterized by a more rapid progression, being diffuse, affecting more often the left main and multiple vessels as compared with non-diabetic patients. This is often because myocardial ischemia in diabetic patients typically occurs without symptoms resulting more incidence of multi-vessel coronary atherosclerosis at time of the diagnosis. ${ }^{4}$

There were several limitations to our study including smaller size of the diabetic patients group because of selection of patients was not based on their diabetic status, when the original study was designed, and various demographic differences between the two patient groups at baseline. In the future, study with larger sample size to confirm the result is needed.

\section{Conclusion:}

Diabetic patients with CAD are more likely to have severe and extensive coronary artery involvement. Left main stem and triple vessel disease were more commonly seen in diabetic patients compared to non diabetic patient. Hence, routine check-up, adoption of lifestyle changes and medications might decrease cardiovascular complications and morbidity from diabetes mellitus.

\section{References:}

1. John FB, Rachel D, Rosanna T. Epidemiology of Coronary Artery Disease. In: Dr. David G, Ed. Coronary Artery Disease - Current Concepts in Epidemiology, Pathophysiology, Diagnostics and Treatment. ISBN: 978-953-51-0262-5, InTech 2012, Available from: http://www.intechopen.com/ books/coronary-artery-disease-current-concepts-inepidemiology-pathophysiologydiagnostics-and-treatment/ epidemiology-of-coronary-artery-disease. 
2. Malik A. Congenital and acquired heart diseases- a survey of 7062 patients. BMRC Bulletin 1976; Vol II No. 2: 115-119.

3. Malik A, Haque S. 'Problems of Cardiovascular Diseases: Prevention and control of cardiovascular diseases. Bangladesh prospective'. Seminar on Control and prevention of cardiovascular diseases in association of Bangladesh. Organized by JICA- Alumni Association of Bangladesh; 2002 Sept 17. p.11.

4. McGuire DK. Diabetes and the Cardiovascular System. In: Libby P, Bonow RO, Mann DL, Zipes DP, editors. Braunwald's Heart Disease: A Textbook of Cardiovascular Medicine. $8^{\text {th }}$ ed. Philadelphia: Saunders; 2008. p. 1392-1410

5. Baim DS. Cardiac Cathete History and Current Practice Standards. In: Baim DS, Grossman W, eds. Grossman's cardiac catheterization, angiography and intervention. $6^{\text {th }}$ ed. Baltimore: Lippincott, Williams \& Wilkins; 1998.

6. 32. Ryan TJ, Faxon DP, Gunnar RM, et al. Guidelines for percutaneous transluminal coronary angioplasty. A report of the American College of Cardiology/ American Heart Association Task Force on Assessment of Diagnostic and Therapeutic Cardiovascular Procedures (Subcommittee on Percutaneous Transluminal Coronary Angioplasty). Circulation 1988;78: 486 -502.

7. Bogaty P, Brekcker SJ, White SE, Stevenson RN, El-Tam\& $\mathrm{H}$, Balcon R, Maseri A. Comparison of coronary angiographic findings in acute and chronic first presentation of ischemic heart disease. Circulation 1993;87: 1938-1946.

8. Biter S, Kern MJ. Angiographic data. In Kern KJ, ed. The cardiac catheterization handbook, $4^{\text {th }}$ edn, Mosby, Stylus, Missouri, USA, 1999. p. 224-247

9. Gensini GG (1983) A more meaningful scoring system for determining the severity of coronary heart disease. Am J Cardiol 51(3): 606.

10. Jinnah CMK, Khan MAH, Molla GM, Rahman MR, Arslan MI. Diabetes Mellitus in Patients with Coronary Heart Disease. Medicine Today2013;25(2):67-68.

11. Shah BS, Deshpande SS. Assessment of demographics, treatment strategies, and evidence-based medicine use among diabetic and non-diabetic patients with acute coronary syndrome: a cohort study. J Pharmacol Pharmacother. 2014;5(2):139-144.

12. Peter A, Hanspeter B-La R, Thomas F, Thomas M, Markus S, Walter A, Hans R. Coronary Anatomy and Left Ventricular Ejection Fraction in Patients With Type 2 Diabetes Admitted for Elective Coronary Angiography. Catheterization and Cardiovascular Interventions 2004; 62:432- 438.
13. Hoque MH, Sufia R, Siddique MA, Ahsan SA, Ahmed CM, Zaman SMM, Mahmood M, Mukhlesur R, Khurshed MA, Sulltan MAU. Coronary Stenting in Diabetic Patients: Evaluation of Immediate Procedural Success \& Adverse Outcomes. University Heart Journal 2010; 6 (1): 3-8

14. Mahadeva S, Sydney C D’Souza, Padmanabha K. Comparison of Severity of Coronary Artery Disease in Diabetic and NonDiabetic Subjects using Gensini Score in Indian Subjects.J Diabetes Metab 2014; 5(12): 469 doi:10.4172/21556156.1000469

15. Muataz FH. Clinical and Angiographic Findings in Diabetic Vs NonDiabetic Iraqi Patients with Ischemic Heart Disease : (A Single Center Experience). THE IRAQI POSTGRADUATE MEDICAL JOURNAL 2011; 10(3): 339-346

16. Morteza E, Asghar P, Shima S, Mohammad K. Comparing the Severity of Coronary Artery Stenosis in Diabetic and Nondiabetic Patients. Biotech Health Sci. 2014 May; 1(1): e19189

17. Mahdi M, Ebrahim N, Maryam M. Comparison of Extent of Coronary Artery Disease in Angiography of Diabetics and Non-Diabetics. Iranian Heart Journal 2006; 7 (4):37-42

18. Shafiuddin, .M. Coronary Angiographic Comparison between Unheralded Acute Myocardial Infarction and Uncomplicated Stable Angina Pectoris. MD thesis, Dhaka University, Bangladesh; 1998.

19. Javidi D, Gharaei B, Fateh S. Cardiovasvular Journal of Southern Africa 2005; 1015: 9657-62.

20. Kassaian SE, Sahebjam M, Salarifar M, Alidoosti M, Zeinali $\mathrm{AH}$, Saleh DK et al. Predictors of Long-term Outcome in Patients with Acute Coronary Syndrome Undergoing Percutaneous Coronary Intervention: A single center registry (THCR). The Journal of Tehran University Heart Center. 2006;1(3) : 155-161

21. Srinidhi SH, P Mallesh, SM Yeli, Veeranna MG, Giri PM. Comparitive Angiographic Profile in Diabetic and NonDiabetic Patients with Acute Coronary Syndrome. Journal of Clinical and Diagnostic Research. 2014 Sep; 8(9): 7-10

22. V. Peppes, A. Panoutsopoulos, G. Rammos, N. Zakopoulos. The association of diabetes mellitus with the severity of angiographic findings in patients with newly-diagnosed coronary artery disease. Arch Hellen Med, 28(2), MarchApril 2011, 245-250

23. Cezary S, Ewa J-S, Jacek W, Bogdan J, Rafa ${ }^{3}$ D, Andrzej S, Andrzej W, Adam O, Hanna S, Witold R. Primary coronary intervention in diabetic octogenarians with acute ST elevation myocardial infarction. Kardiologia Polska 2007; 65: 1181-1185 